\title{
Malaria treatment policies and drug efficacy in Haiti from 1955-2012
}

\author{
Michael E von Fricken ${ }^{1,2^{*}}$, Thomas A Weppelmann ${ }^{1,2}$, Jennifer D Hosford ${ }^{2}$, Alexander Existe ${ }^{3}$ \\ and Bernard A Okech ${ }^{1,2}$
}

\begin{abstract}
Objectives: Chloroquine (CQ), after 67 years of use in Haiti, is still part of the official treatment policy for malaria. Several countries around the world have used CQ in the past due to its low incidence of adverse events, therapeutic efficacy, and affordability, but were forced to switch treatment policy due to the development of widespread CQ resistance. The purpose of this paper was to compile literature on malaria treatment policies and antimalarial drug efficacy in Haiti over 67-year period.
\end{abstract}

Methods: A systematic review of PubMed, Web of Science, and the Armed Forces Pest Management Board, was conducted to find pertinent documents on national malaria treatment policies and antimalarial drug efficacy studies in Haiti between 1955 and 2012. A total of 329 citations and abstracts were reviewed independently by two researchers, of which thirty three met the final inclusion criteria of studies occurring in Haiti between 1955 and 2012 which specifically discuss malaria treatment policies and drug efficacy.

Results: Results suggest that CQ has been the predominant antimalarial drug in use from 1955 to 2012. In 2010 single dose primaquine $(\mathrm{PQ})$ was added to the national treatment policy, however it is not clear whether this new policy has been put into practice.

Conclusions: Although no widespread CQ resistance has been reported, some studies have detected low levels of CQ resistance. Increased surveillance and monitoring for CQ resistance should be implemented in Haiti.

Keywords: Hispaniola, Haiti, Malaria treatment policy, Chemotherapy, Chloroquine, Anti-malarial drug resistance, Plasmodium falciparum, Pyrimethamine

\section{Introduction}

Malaria persists in Hispaniola despite its elimination from other Caribbean countries [1]. It's estimated that over 99\% of malaria cases in Haiti are caused by Plasmodium falciparum with Anopheles albimanus serving as the principal mosquito vector [2-4]. The burden of malaria is high in Haiti, relative to its population of 10 million people, with $80 \%$ of the Haitian population living in areas where malaria is endemic [5,6]. Historically, Haiti has under-reported the number of malaria cases, largely due to limited resources, inadequate surveillance and a shortage of trained personnel [7-9]. The antimalarial chloroquine (CQ) has been relied

\footnotetext{
* Correspondence: Michaelvonfricken@epi.ufl.edu

${ }^{1}$ Department of Environmental and Global Health, University of Florida, P.O. Box 100188, Gainesville, FL 32610, USA

${ }^{2}$ Emerging Pathogens Institute, University of Florida, P.O. Box 100009,

Gainesville, FL 32610, USA

Full list of author information is available at the end of the article
}

on heavily in Haiti, due to its low incidence of adverse events, affordability, and perceived therapeutic efficacy, despite the emergence of CQ resistance globally.

To better understand Haiti's prolonged commitment to $\mathrm{CQ}$, we compiled reports and publications on malaria chemotherapeutic policies and antimalarial resistance in Haiti from 1955 to 2012 based on a systematic search of historical literature. Prior to 1955, quinine was used intermittently during periods of US occupation [10]. The purpose of this paper is to document the history of Haiti's malaria treatment policies, while providing a useful reference for antimalarial drug resistance studies in Haiti.

\section{Methods \\ Data sources \\ Published studies and reports about malaria in Haiti were identified from an electronic search of MEDLINE $\%$}


PubMed $^{\bullet}$ (1955-2012) and Web of Science (1955-2012). A search of gray literature was carried out on the Armed Forces Pest Management Board (AFPMB) database [11], which contains publications and reports from the Centers for Disease Control and Prevention (CDC), World Health Organization (WHO), and Pan American Health Organization (PAHO). Search terms were chosen to capture malaria treatment policy and drug efficacy studies in Haiti only, using a combination of simple subject headings and term combinations, focusing on treatment, malaria, and Haiti.

\section{Study selection}

The selection criteria of the data sources included are; 1 ) reports from the period of 1955 to 2012, 2) all studies carried out in Haiti, 3) and studies that discuss malaria. Full text manuscripts and all citations which met the predefined selection criteria were obtained and examined by two independent researchers. Final inclusion and exclusion decisions were made with $100 \%$ agreement between the examiners based on studies that reported malaria treatment policies and drug efficacy for final inclusion. Where duplications were observed the most recent version of the manuscript was selected. The year 1955 was used as a start date for analysis, because it coincided with the Global Malaria Elimination Program campaign in Haiti.

\section{Results}

A total of 329 citations and abstracts in the electronic searches were found. Of these, 85 citations and abstracts met the preliminary criteria and their full texts were reviewed. Thirty three studies described malaria treatment policies or antimalarial drug efficacy in Haiti from 1955-2012 [1,2,4,6-9,12-37].

\section{Characteristics of included studies}

Chloroquine was first introduced in Haiti in 1955, when The Eighth World Health Assembly recommended its use in combination with pyrimethamine $(\mathrm{P})$ for the elimination of malaria. The chloroquine/pyrimethamine $(\mathrm{CQ} / \mathrm{P})$ combination strategy was the first treatment policy switch in Haiti replacing the previous accepted practice of quinine for the treatment of malaria [38-40]. According to the data sources, from 1955 to $1970, \mathrm{CQ} / \mathrm{P}$ was administered in a prophylactic manner through mass drug administration (MDA) campaigns, as part of the Global Malaria Eradication Program in Haiti $[13,15,16,40]$. From 1970 to 2010, the treatment for malaria switched from a combination therapy of $\mathrm{CQ} / \mathrm{P}$ therapy to $\mathrm{CQ}$ monotherapy for uncomplicated malaria cases [16]. In 2010 a CDC report mentioned the addition of the transmission blocking drug primaquine $(\mathrm{PQ})$ at a single dose of $0.75 \mathrm{mg} / \mathrm{kg}$, suggesting a major change in policy [36]. All final articles $(\mathrm{N}=33)$ that we evaluated reported $\mathrm{CQ}$ as or part of the standard treatment policy in Haiti. A brief summary of treatment policies can be seen in the timeline provided (Figure 1).

\section{Evidence for treatment resistance in Haiti}

Only fourteen studies from the data sources examined $[6,9,12-19,21,26,32,35]$ discussed chemotherapeutic efficacy or patient treatment outcome data (Table 1). Six of these fourteen studies contained documentation of resistance to CQ or P $[6,16,18,19,21,32]$. The first year of reported of anti-malarial resistance, where $P$. falciparum had documented pyrimethamine resistance was 1971 [16]. In 1982, a report of possible resistance to CQ treatment was suggested [6] after a patient on CQ monotherapy had resurgence in parasitemia on day 28 of treatment. A follow-up in vitro test found 4/16 P. falciparum cultures including the $P$. falciparum strains from the patient with resurgent parasitemia, required CQ doses large enough that suggested possible resistant $P$. falciparum parasites. This report provided the first credible in vitro evidence of P. falciparum resistance to CQ in Haiti [18]. In 1984, an in vivo and in vitro study, tested for $P$. falciparum parasite resistance to sulfadoxine/pyrimethamine (S/P) [19] to provide baseline data on susceptibility in the event that CQ resistance developed in Haiti. The results indicated parasite resistance to pyrimethamine alone, but not to sulfadoxine. Despite in vitro evidence of resistance to pyrimethamine, all in vivo infections were susceptible to a combination of S/P [19]. In 1985, another in vivo study to complement the previous in vitro assay found resistance to pyrimethamine alone [21]. More recently, a report by Londono et al, has documented the detection of genetic

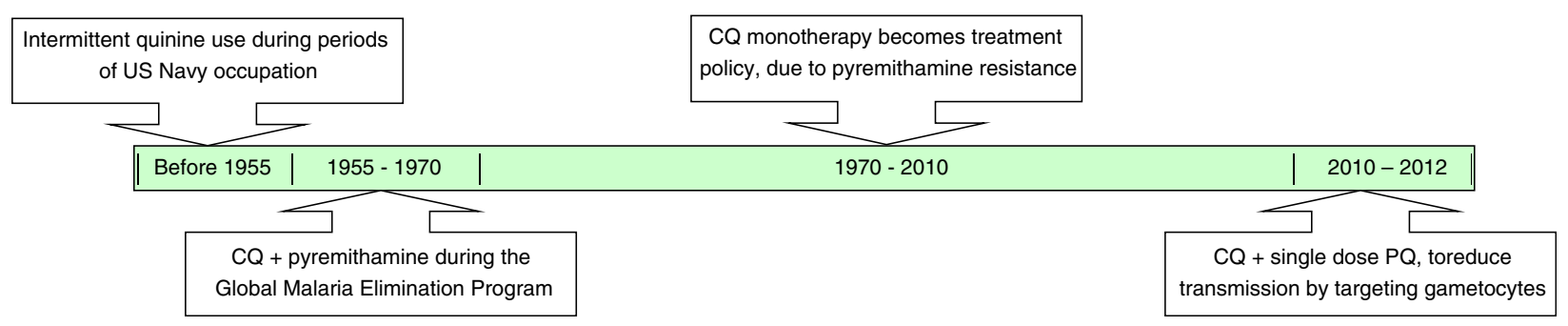

Figure 1 Timeline of Haitian malaria treatment policies. 
Table 1 Reports of treatment efficacy for malaria in Haiti

\begin{tabular}{|c|c|c|c|c|c|c|c|}
\hline Period & $\begin{array}{l}\text { Sample } \\
\text { size }\end{array}$ & Site in Haiti & $\begin{array}{c}\text { Drug } \\
\text { combination }\end{array}$ & $\begin{array}{l}\text { Source of } \\
\text { data used }\end{array}$ & Resistant & Susceptible & Reference \\
\hline $\begin{array}{l}1960- \\
1966\end{array}$ & N/A & Country Wide & $\mathrm{CQ} / \mathrm{P}$ & Secondary & $\mathrm{N} / \mathrm{A}$ & CQ & PAHO. 1967 [14] \\
\hline 1961 & N/A & Country Wide & $\mathrm{CQ}$ & Secondary & N/A & CQ & WHO. 1965 [13] \\
\hline $\begin{array}{l}1962- \\
1965\end{array}$ & N/A & Country Wide & $\mathrm{CQ} / \mathrm{P}$ & Secondary & N/A & $\mathrm{CQ} / \mathrm{P}$ & $\begin{array}{l}\text { Mason J and Philippe A, } 1967 \\
\text { [12] }\end{array}$ \\
\hline $\begin{array}{l}1962- \\
1965\end{array}$ & N/A & Petitie Goave & $C Q \& C Q / P$ & Secondary & N/A & $\mathrm{CQ} / \mathrm{P}$ & WHO, 1968 [15] \\
\hline 1971 & N/A & Country Wide & $\mathrm{CQ}$ & Secondary & $\begin{array}{l}\text { W, P \& } \\
\text { CG }\end{array}$ & CQ & WHO, 1972 [16] \\
\hline 1976 & N/A & Country Wide & N/A & Secondary & N/A & $C Q$ & WHO, 1978 [17] \\
\hline 1980 & N/A & Country Wide & $C Q$ & Secondary & N/A & W CQ & PAHO, 1980 [9] \\
\hline $\begin{array}{l}1981- \\
1983\end{array}$ & 92 & $\begin{array}{l}\text { Les Cayes, Port-au-Prince, Limbe, } \\
\text { Gros-Morne and Jacmel }\end{array}$ & $\mathrm{CQ}$ & Secondary & $\begin{array}{l}V T \& W \\
C Q\end{array}$ & $\mathrm{CQ}$ & $\begin{array}{l}\text { Duverseau YT, Magloire R, et al., } \\
1986 \text { [6] }\end{array}$ \\
\hline 1982 & 19 & Port-au-Prince & $C Q$ & Secondary & $\begin{array}{l}\mathrm{VT} \& \mathrm{~W} \\
\mathrm{CQ}\end{array}$ & N/A & $\begin{array}{l}\text { Magloire R and Nguyen-dinh P, } \\
1983 \text { [18] }\end{array}$ \\
\hline 1982 & 18 & Port-au-Prince & $P \& S / P$ & Primary & $\begin{array}{l}V T \& W \\
P\end{array}$ & W S/P & $\begin{array}{l}\text { Nguyen-Dinh P, Zevallos-Ipenza } \\
\text { A, et al., } 1984 \text { [19] }\end{array}$ \\
\hline 1985 & 22 & Port-au-Prince & $P \& S / P$ & Primary & $V T P$ & $W \& V T S / P$ & $\begin{array}{l}\text { Nguyen-Dinh P, Payne D, et al., } \\
1985 \text { [21] }\end{array}$ \\
\hline 1995 & N/A & Country Wide & N/A & Primary & N/A & W CQ & $\begin{array}{l}\text { Drabick JJ, Gambel JM, et al., } \\
1997 \text { [26] }\end{array}$ \\
\hline $\begin{array}{l}2006- \\
2007\end{array}$ & 79 & Artibonite Valley & $C Q$ & Secondary & PCR CQ & N/A & $\begin{array}{l}\text { Londono BL, Eisele TP, et al., } \\
2009 \text { [32] }\end{array}$ \\
\hline $\begin{array}{l}2010- \\
2011\end{array}$ & 49 & Leogane & $C Q$ & Primary & N/A & PCR CQ & $\begin{array}{l}\text { Neuberger Zhong K, et al., } 2012 \\
\text { [36] }\end{array}$ \\
\hline
\end{tabular}

Key: Chloroquine $(\mathrm{CQ})$, pyrimethamine $(\mathrm{P})$, chloroquine with pyrimethamine $(\mathrm{CQ} / \mathrm{P})$,sulfadoxine with pyrimethamine (S/P), in vivo susceptibility $(\mathrm{VV})$, in vitro susceptibility (VT), DNA examined for mutations via polymerase chain reaction (PCR).

markers via PCR, for CQ resistance in five of 79 patients (6\%) from the Artibonite Valley [32]. However, a study by Neuberger et al, found zero of 49 infected patients to have mutations suggestive of CQ resistance [36]. These studies present conflicting evidence about the presence or absence of CQ drug resistance in the populations studied, with no definitive documentation of in vivo resistance reported.

\section{Discussion}

Following the widespread use of CQ/P from 1955-1968, resistance to pyrimethamine was reported in Haiti in 1971 [16]. It was suggested that parasite adaptation to pyrimethamine had occurred due to selective drug pressure from the MDA campaign, which ended in 1968, resulting in its removal from the national treatment policy $[16,19]$.

Haiti continued to rely predominantly on CQ as part of the treatment for malaria in Haiti up until 2010, when single dose PQ was added to the official policy for the treatment of uncomplicated malaria in Haiti [2,37]. Haiti represents a unique scenario where $\mathrm{PQ}$ has not been used previously on the island due to the absence of Plasmodium vivax, but is being introduced to specifically block malaria transmission by targeting the adult stage
Plasmodium falciparum parasites. It remains unclear whether or not PQ has been implemented in practice, nor have any studies examined population rates of G6PD deficiency in Haiti, a genetic mutation that places deficient individuals at risk of acute hemolytic anemia when exposed to PQ.

Overall, we found the use of CQ has featured prominently in the management of malaria in Haiti for decades. While CQ resistance in many South and Central American countries has forced these countries to change policies, the Haitian Ministry of Health (MSPP) has continued to rely almost entirely on CQ as the principal treatment for malaria. Despite such prolonged use, our results found no conclusive evidence of the presence or absence of CQ resistance in Haiti (Table 1). However, findings from the studies that report on treatment sensitivity are lacking due to small sample sizes $[6,18,19,21,32,36]$, localized enrollment $[6,15,18,19,21,32,36]$, and missing information on patient treatment outcomes, significantly limiting their ability to influence national treatment policies (Table 1). Ten of the fourteen studies that make mention of drug efficacy, relied solely on secondary sources of data, often only containing brief comments on treatment effectiveness, which further suggest an absence of designed drug sensitivity studies 
occurring in Haiti $[6,9,12-18,32]$. The two most recent studies examining CQ resistance by Londono and Neuberger gave different results about the presence of genetic markers of CQ resistance in Haiti $[32,36]$. However, both studies had small sample sizes of 79 and 48 respectively and were located in different regions of the country. CQ resistance mutations are emerging in Haiti, but to what extent remains unknown, suggesting a need for increased surveillance for parasite resistance.

\section{Limitations}

We were unable to examine gray literature from the MSPP as most documents were lost during the 2010 earthquake. Although we excluded non-English databases, we believe this omission to not be very significant, since we relied heavily on WHO and PAHO reports, which are based on both English and non-English databases and reports. There were limited data pertaining to treatment failures and parasite resistance, in addition to an overall lack of reporting between 1985-2005 due to political unrest $[8,32]$.

\section{Conclusions}

As of 2012, the few documented reports of CQ resistance in Haiti did not exceed the WHO recommended threshold treatment failure rate of $\geq 10 \%$ [41]. However, due to limited surveillance on drug efficacy and barriers to patient follow up, further studies are necessary to determine if rates of CQ resistance fall below this threshold in Haiti. Meanwhile, Non-government organizations, foreign aid agencies, and the Haitian MSPP should consider implementing a comprehensive malaria control program while CQ remains a viable treatment option $[32,35,36]$. Other drug regimens, such as artemisininbased combination therapies, are part of an arsenal of available treatment options, in the event of CQ resistance. The affordable cost of CQ, and its' low incidence of adverse events make it an ideal treatment option on a large scale. It is our recommendation that increased surveillance and monitoring for $C Q$ resistance be implemented, due to significant gaps in data on CQ treatment failure and resistance in Haiti. Regarding the recent addition of $\mathrm{PQ}$ to the national policy, more information is needed on how PQ is tolerated in this population, given the absence of information on G6PD prevalence rates, and whether or not this policy has been put into practice in Haiti. Future studies examining transmission rates in Haiti may generate valuable information on the impact single dose PQ has on malaria rates, potentially providing a template for elimination in other low transmission settings globally.

\section{Abbreviations}

CQ: Chloroquine; P: Pyrimethamine; CQ/P: Combined chloroquinepyrimethamine; PQ: Primaquine; S: Sulfadoxine; S/P: Combined sulfadoxine- pyrimethamine; ACT: Artemisinin-based combination therapy; WHO: World Health Organization; PAHO: Pan American Health Organization; MSPP: Ministry of Health and Population; MDA: Mass Drug Administration.

\section{Competing interests}

The authors declare that they have no competing interests.

\section{Author details}

${ }^{1}$ Department of Environmental and Global Health, University of Florida, P.O. Box 100188, Gainesville, FL 32610, USA. Emerging Pathogens Institute, University of Florida, P.O. Box 100009, Gainesville, FL 32610, USA. ${ }^{3}$ National Laboratory of Public Health, Ministry of Public Health and Sanitation, Angle Delmas 33 et Rue Charbonnieres, Haiti.

Received: 4 September 2013 Accepted: 7 November 2013

Published: 11 November 2013

\section{References}

1. Roberts L: Tuberculosis and malaria elimination meets reality in Hispaniola. Science 2010, 328:850-851.

2. World Health Organization: World Malaria Report 2010. Geneva: WHO; 2011

3. Hobbs JHSJ, St Jean Y, Jacques JR: The biting and resting behavior of Anophele albimanus in northern Haiti. J Am Mosa Control Assoc 1986, 2:150-153.

4. Krogstad DJ, Joseph VR, Newton LH: A prospective study of the effects of ultralow volume (ULV) aerial application of Malathion on Epidemic Plasmodium falciparum Malaria IV Epidemiological aspects. Am J Trop Med Hyg 1975, 24:199-205.

5. Roll Back Malaria: Global Malaria Action Plan For a Malaria-free world Geneva: WHO Global Malaria Programme. Geneva: WHO; 2008.

6. Duverseau YT, Magloire R, Zevallos-Ipenza A, Rogers HM, et al: Monitoring of Chloroquine sensitivity of Plasmodium Falciparum in Haiti, 1981-1983. Am J Trop Med Hyg 1986, 35:459-464.

7. Pan American Health Organization: Haiti: Epidemiological Situation (1996-1999). Washington, D.C: PAHO; Epidemiol Bull; 2000:19-20.

8. Kachur SP, Nicolas E, Jean-François V, Benitez A, et al: Prevalence of Malaria Parasitemia and accuracy of microscopic diagnosis in Haiti, October 1995. Rev Panam Salud Publica 1998, 3:35-39.

9. Pan American Health Organization: Status of Malaria Eradication Programs, Volume 1. Washington, D.C: PAHO Epidemiol Bull; 1980:1-5.

10. Cook SS: Malaria control in Haiti. South Med J 1930, 23:454-458.

11. Department of Defense Armed Forces Pest Management Board: Literature Retrieval System. Washington, D.C: DoD; 2012. Available at http://www. afpmb.org/content/literature-retrieval-system.

12. Mason J, Philippe AN: Malaria epidemic in Haiti following a hurricane. Am J Trop Med Hyg 1965, 14:533-540.

13. World Health Organization: Malaria Eradication in 1965. Geneva: WHO; 1965:286-300

14. Pan American Health Organization: Report on the Status of Malaria Eradication in the Americas. Washington, D.C: PAHO Epidemiol Bull; 1967:1-120.

15. World Health Organization: Development of the Haiti Malaria Eradication Programme. Geneva: WHO; 1968:4-20.

16. World Health Organization: Malaria Eradication in 1971. Geneva: WHO Technical Report Series; 1972:485-496.

17. World Health Organization: The Malaria Situation in 1976. Geneva: WHO Chron; 1978:9-17.

18. Magloire R, Nguyen-dinh P: Chloroquine susceptibility of Plasmodium falciparum in Haiti. Bull World Health Organ 1983, 61:1017-1020.

19. Nguyen-Dinh P, Zevallos-Ipenza A, Magloire R: Plasmodium falciparum in Haiti: susceptibility to Pyrimethamine and Sulfadoxine-Pyrimethamine. Bull World Health Organ 1984, 62:623-626.

20. Pan American Health Organization: Status of Malaria Programs in the Americas. Washington, D.C: PAHO. Epidemiol Bull; 1984:1-51.

21. Nguyen-Dinh P, Payne D, Teklehaimanot A, Zevallos-Ipenza A, et al: Development of an in vitro microtest for determining the susceptibility of Plasmodium falciparum to Sulfadoxine-Pyrimethamine: laboratory investigations and field studies in Port-au-Prince Haiti. Bull World Health Organ 1985, 63:585-592.

22. Pan American Health Organization: Malaria control in the Americas: a critical analysis. Washington, D.C. Bull Pan Am Health Organ 1986, 20:9-17. 
23. Deloron P, Duverseau YT, Zevallos-Ipenza A, Magloire R, et al: Antibodies to Pf155, a major Antigen of Plasmodium Falciparum: Seroepidemiological studies in Haiti. Bull World Health Organ 1987, 65:339-344.

24. Pan American Health Organization: Malaria in the Americas. Washington, D.C. Bull Pan Am Health Organ 1992, 13:1-6.

25. Bonnlander $\mathrm{H}$, Rossignol AM, Rossignol PA: Malaria in central Haiti: a hospital-based retrospective study, 1982-1986 and 1988-1991. Bull Pan Am Health Organ 1994, 28:9-16.

26. Drabick JJ, Gambel JM, Huck E, De Young S, et al: Microbiological laboratory results from Haiti: June-October 1995. Bull World Health Organ 1997, 75:109-115.

27. Pan American Health Organization: Vollume II: health in the Americas 1998. Washington, D.C. Bull Pan Am Health Organ 1998, 2:316-330.

28. Vanderwal T, Paulton R: Malaria in the Limbé River valley of northern Haiti: a hospital-based retrospective study, 1975-1997. Am J Public Health 2000, 7:162-167.

29. Pan American Health Organization: Situation of malaria programs in the Americas. Washington, D.C. Bull Pan Am Health Organ 2001, 22:10-14

30. Eisele TP, Keating J, Bennett A, Londono B, et al: Prevalence of Plasmodium falciparum infection in rainy season, Artibonite Valley, Haiti, 2006. Emerg Infect Dis 2007, 13:1494-1496.

31. Keating J, Eisele TP, Bennett A, Johnson D, et al: A description of malaria-related knowledge, perceptions, and practices in the Artibonite Valley of Haiti: implications for malaria control. Am J Trop Med Hyg 2008, 78:262-269

32. Londono BL, Eisele TP, Keating J, Bennet A, et al: Chloroquine-resistant Haplotype Plasmodium falciparum parasites Haiti. Emerg Infect Dis 2009, 15:735-740.

33. Adams P: Rainy season could hamper Haiti's recovery. Lancet 2010, 375:1067-1069.

34. Center for Disease Control and Prevention: Malaria Acquired in Haiti - 2010 Atlanta, GA: CDC MMWR; 2010:217-219.

35. Townes $D$, Existe A, Boncy J, Magloire R, et al: Malaria survey in postearthquake Haiti-2010. Am J Trop Med Hyg 2012, 86:29-31.

36. Neuberger A, Zhong K, Kain KC, Schwartz E: Lack of evidence for chloroquine-resistant Plasmodium falciparum malaria, Leogane Haiti. Emerg Infect Dis 2012, 18(9):1487-1489.

37. Centers for Disease Control and Prevention: Malaria in Post-Earthquake Haiti: CDC's Recommendations for Prevention and Treatment. Atlanta, GA: CDC Alerts; 2010

38. Centers for Disease Control and Prevention: The History of Malaria, an Ancient Disease. Atlanta, GA: CDC; 2010.

39. International Cooperation Administration: Malaria Manual, For U.S. Technical Cooperation Programs, Public Health Division. Washington D.C: ICA; 1956.

40. World Health Organization: The Eighth World Health Assembly. Geneva: WHO; 1955.

41. World Health Organization: Guidelines for the treatment of malaria, Volume 2. WHO; 2010. Available at http://www.who.int/malaria/publications/atoz/ 9789241547925/en/index.html.

doi:10.1186/2052-3211-6-10

Cite this article as: von Fricken et al.: Malaria treatment policies and drug efficacy in Haiti from 1955-2012. Journal of Pharmaceutical Policy and Practice 2013 6:10.

\section{Submit your next manuscript to BioMed Central and take full advantage of:}

- Convenient online submission

- Thorough peer review

- No space constraints or color figure charges

- Immediate publication on acceptance

- Inclusion in PubMed, CAS, Scopus and Google Scholar

- Research which is freely available for redistribution

Submit your manuscript at www.biomedcentral.com/submit
Biomed Central 